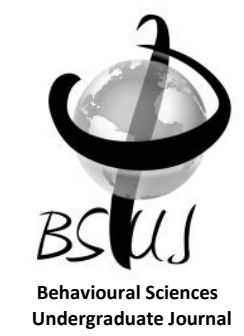

\title{
Defining Desire, Dispelling Defiance: Heteronormative Language in English Language Learner's Dictionaries
}

BSUJ 1(1)

http://mrujs.mtroyal.ca/ index.php/bsuj

\author{
Janelle Harms $\mathbf{a}^{\mathrm{a}}$
}

\begin{abstract}
Monolingual learner's dictionaries (MLDs) strive to use accessible, comprehensive and ostensibly objective language to communicate ideas to those with intermediate to advanced language proficiency. However, it will be argued that MLDs of the English language are not objective, but rather ideological documents in which discursive authority stems from the production of knowledge. In their representations of sex, gender and sexual desires and identities, MLDs venerate reproductive heterosexuality as the correct, normal and 'natural' mode of human expression while erasing queer realities and possibilities. As a result, queer English language learners are marginalised as imperfect citizens and are compelled to embody heterosexual culture in both language and behaviour in order to achieve increased legitimacy within the English-speaking nation-state.
\end{abstract}

Keywords: critical discourse analysis, English language learner, gender, heteronormativity, hijra, sex, sexuality, two-sex, queer theory

Through the process of learning English as a new language, the non-native speaker will encounter language-specificand, as language learning is often crosscultural and cross-national-culture-specific conceptualisations of the nature of the world. Stepping into a new cultural milieu requires an understanding of the unfamiliar culture's unique frameworks and strategies for systematically capturing ideas in words. English language learners (ELL) seeking clear and correct explanations of English terms can consult several types of reference materials, including general-purpose dictionaries, written for native speakers and offering comprehensive definitions as well as synonyms to fully explain concepts; bilingual dictionaries, providing direct word-to-word translations with little if any definition; and monolingual learner's dictionaries (MLDs), using accessible wording, as well as examples of conversational usage, to communicate ideas (Baxter 1980:325).
aMount Royal University
Corresponding Author:
Janelle Harms
jharm298@mtroyal.ca 
Because of the substantial leap in information density and fluency expectation between bilingual and general dictionaries, MLDs help to bridge the gap for those with intermediate to advanced language proficiency. Access is provided for web users via online versions of MLDs offered by such prestigious academic publishers as Cambridge University Press, Oxford University Press, and Merriam-Webster. The professed objective of lexicographers-those who write and edit these dictionaries-is to objectively define terms in accordance with frequent and common usage (Bury 2013). However, learners' dictionaries offer many linguistic explanations that are anything but neutral, nuanced or comprehensive, resulting in essentialist misrepresentations of certain people and the idealization of others.

Monolingual learner's dictionaries of the English language are heteronormative. That is, MLDs both underpin and disseminate a particular discourse which venerates reproductive heterosexuality as the correct, normal and 'natural' mode of human expression. This contention in turn relies upon two conceptual frameworks: firstly, essentialist two-sex models in which humans are essentially either wholly female or wholly male, and secondly, a normalized alignment of sex, gender, and sexuality where masculine men and feminine women desire each other exclusively. Through the analysis of definitions relevant to sex/gender/sexuality, integrated and summarized from five MLDs, evidence suggests that dictionaries, which hold discursive authority over the correct meaning and appropriate use of language, actually limit expression and thus erase queer realities and possibilities. Furthermore, the present paper critiques heteronormativity as a dominant ideological and political project in which queer English language learners are marginalized as doubly imperfect citizens for their failure to fit into the compulsory institutions of marriage (conjugal heterosexuality) and family (procreative sex) in the English-speaking nation. ELL and queer people alike are subsequently expected to imitate the ideal citizen, who embodies heterosexuality in both language and behaviour, in order to achieve increased legitimacy within the heteronormative nation-state.

Cross-cultural studies (Nanda 1985; Goulet 2001; Gannon 2011) have found that there are indeed understandings of sex/gender/sexuality that exist outside of the alignment of those elements which support the heteronormative binary. The hijra of India is one such example of a construction of cultural performance of gender that does not necessarily fall into this alignment. Much of the hijra's gender performance is recognized as feminine, adopting a blend of femaleassociated names, dress and grooming habits, mannerisms, and speech (Nanda 1985:228). Contrary to popular constructions and understandings of the hijra as emasculated men (Nanda 1985:226), these people selfdescribe as "neither man nor woman", being "born as men, but not men" (Nanda 1985:227), and they play the institutionalized role of a third gender in Indian society (p. 235). The hijra help illustrate the idea of liminality-an unstable, ambiguous, inbetween state-for gender variant individuals who, regardless of the normalized framework in which they are often placed, do not identify as either male or female in gender roles, sex, or sexuality.

As for monolingual learner's dictionaries, what narratives do they offer? What are English language learners being taught about sex, gender and sexualities in the English-speaking world? In Appendix A, it can be clearly seen that definitions in these MLDs (CLD, MEDAL, MWLD, LED, OALD-the full MLD sources are also listed in Appendix A) pertaining to sex/gender/sexuality have been fragmented and manipulated to the point where people who do not fit into the heteronormative binary of male/female heterosexuality are easily discursively marginalized as abnormal.

\section{LANGUAGE (UN)LEARNING: AN OVERVIEW OF QUEER THEORY}

The narratives of sex, gender, and sexuality communicated by MLDs are 
problematic when scrutinized through a postmodern queer theoretical lens. Queer theory interrogates behaviour and 'identity' as it falls into 'normative' and 'deviant' categories and highlights instability within the normative match of sex, gender and desire. A dictionary is meant to be a cultural mirror-an objective representation of common meanings delivered without bias (Bury 2013). When analysing such a cultural document, however, a critical perspective considers the power relations and ideological pressures that brought the text into being through processes of selective inclusion and exclusion (Foucault 1990:27). Queer theory problematizes cultural assumptions that are initially difficult to perceive because of their very ubiquity, and it seeks to unpack the authority of dominant cultural assumptions of gender, sexuality, bodies, acts and desires (Turner 2004:481-82). As such, while it overlaps with the aims of LGBT studies, queer theory is critical of sexuality as an identity, as such labels and classifications often rely on those same problematic assumptions, as well as contributing to identity politics that may continue to do violence to oppressed groups (Turner 2004:481-2). Michael Warner (1993), a prominent social theorist and queer theorist, impels the reader to critically consider the ubiquity of heterosexual culture, highlighting that "the logic of the sexual order is so deeply embedded by now in an indescribably wide range of social institutions..." (xiii). Warner describes how heterosexual culture is actively constructed as "the elemental form of human association, as the very model of inter-gender relations, as the indivisible basis of all community, and as the means of reproduction without which society wouldn't exist" (xxi). Heterosexual culture commands discursive space, and this pushes subordinate culture (i.e., queer culture) to the fringes of society.

Michel Foucault (1990) investigates the relationship between knowledge and power, where discourse is created and shaped through language; knowledge bestows particular actors the authority to generate the dominant discourse, and to determine what can be said, which in turn determines what can be known (p. 23-4). The practice of misrepresenting or even omitting queer terms from the dictionary is problematic in that it points to a particular ideological slant, as discussed by Ball (1998:25), rendering queer folk invisible in society. For Foucault (1990), silence, too, is powerful; that which is left unsaid, taken for granted or framed as common sense, speaks volumes about the presumed knowledge of social actors. Discourses are also governable and those with social and political power control the discourse of sexuality; control over discourse equates to control, too, over sexualities (p. 25), for labelling and classification enables control.

Sexual identities are political labels, and ones that have historically been used as weapons rather than merely ways of describing. Turner (2004:482) notes that "the process of defining an identity category enables a process of inclusion and exclusion"; that is, it brings into focus a group of people who then can have power enacted upon them. For those who would be described as lesbian, gay, bisexual, transgender, and/or intersex, these labels are not so much reflecting their lived experience as restricting their experience. Social identity may be used to categorize all persons who exhibit selective characteristics or behaviours, while minimizing intergroup similarities and intragroup differences. Further, these labels redirect societal attention to one's gender identity or choice of partner as a significant and classifiable aspect of one's existence. In other words, it signifies that this specific quality is so essential to who a person is that it is worth singling a person out for.

The word "queer" has a rather volatile history and has evolved considerably over the last two decades. Queer can be a broadly positive term for many non-normative expressions of sex, gender and sexuality, and may be used those who would self-describe as lesbian, gay, bisexual, transgender, and/or intersex (Turner 2004). The positive, reclaimed use of "queer" is recognised by the MWLD and the MEDAL. However, the 
remaining resources either omit the word altogether, or else define it only as an informal and offensive term; most fail to acknowledge that "queer" has taken on a distinctive meaning in the academic world.

While "queer" has a history as a pejorative term for LGBTI people (Turner 2004:481-3), for MLDs to solely identify it as an offensive or taboo word (CLD, LED, MWLD, OALD), while failing to bring attention to more positive connotations of queer, insulates the potentially uninformed reader from the queer movement and sets back those who self-describe as queer in their struggle to reclaim the word. In a similar vein, for the term "tranny" not to be described as offensive (OALD) implies that it, with all of its negative baggage, is an appropriate label for particular bodies, whereas the LGBT antidefamation organization GLAAD's (N.d.) work, Transgender Resources, considers the term offensive and dehumanizing to transgender people.

Judith Butler (1988), who has contributed extensively to feminist and queer theory, argues that sex is as much a cultural construction as gender is (p. 9-11). Butler (1990) explains that treating gender as cultural and sex as material relies upon an essentialist system where binary sex is biological and natural. If sex and gender are treated as separate systems, gender becomes disentangled from material bodies. Butler (1988) argues that there is no stable or core gender identity, only "an identity instituted through a stylized repetition of acts" (p. 519). Butler (1988) compares doing gender to a theatrical performance (p. 521), arguing that gender is 'real' insofar as it is acted out over time and through a set of behaviours that meet expectations (p. 527). Butler (1990) also develops the concept of the heterosexual matrix, where sex, gender and sexuality are expected to align in a common sense (read: heteronormative) way. The LED, MEDAL, and MWLD define males and females solely on the criteria of their ability or inability to produce babies, and the CLD and OALD provide only circular definitions. All of these definitions fall down immediately: reproductive ability is obviously not the sole criterion of femaleness-many women are infertile, for example, and yet they are still considered essentially women. It becomes apparent to the MLD reader, judging from where the editors have chosen to place emphasis (i.e., the procreative imperatives of males and females, the legitimacy of legally recognised partnerships) that the heterosexual reproductive nuclear family is the expectation societal standard for relations between the sexes. The narrative of the dictionary becomes the script of normative behaviour, and the heterosexual state compels good citizens to strive to embody those norms.

Anthropologist David Valentine has studied the emergence of the term 'transgender'; keeping in line with Foucauldian discourse analysis, Valentine (2006) sees desire and identity as socially constructed through discourse, rather than springing forth from natural alignment of binary sex, gender and sexuality. The dictionary definition of 'homosexuality' is incoherent without the presence of two unambiguously sexed bodies, and "the logic of binary gender which underpins homo-hetero identity structure" (Valentine 2006:247) fails to reflect lived experiences. If the normative alignment of sex, gender and sexuality is to be intelligible, then sexual desire, whether 'same-sex' or 'opposite-sex', necessarily relies upon stable gendered subjects in binary opposition-males and females. Such mutually exclusive sexual identity categories are no more reflective of diverse social relationships than the fallacious two-sex model they draw from. Valentine (2006) finds that "use of particular kinds of identity categories disable certain kinds of desires from being validated" (p. 248); he contends that gender and sexuality are inseparable within lived experience, and that speaking of desires (p. 253) allows for fluidity of sexual expression outside of the heterosexual matrix. For example, transgender desires complicate the alignment of gender expression and partner choice (p. 247) that underlies the separation of sex, gender and sexuality, in that they do not neatly fit binary 
categories or expectations. Acknowledgment of this liminal quality of the body renders the double binary, and presumptions of feminine females desiring masculine males and vice versa, incoherent.

\section{STRAIGHT TALK: IMPLICATIONS FOR READERS}

In the five MLDs considered in this paper, conceptualizations of sex, gender, and sexuality are contradictory, nonencompassing, and non-reflective of critical social constructionist readings of current biological, medical-psychological, legal, and sociocultural notions of sex, gender and sexuality. What's more, many recognized nonnormative sexes, genders, and sexualities are misrepresented or ignored outright, reflecting the ubiquity of homophobic, transphobic, and heterosexist attitudes in the linguistic culture. All in all, sex, gender, and sexuality are represented in ways that make them difficult for the reader to 'queer'. Such characterizations are disempowering in that they embed non-normative bodies and desires firmly within the heterosexual matrix.

When the narratives of these MLDs are taken to be true, queer people are tacitly construed as wanting to 'go straight' in an attempt to resolve their own illegitimate expression of sex, gender and/or sexuality. The assumption of binary bender is continuous, with dozens of references to "same-sex" or "opposite-sex" desire. The MLD narrative describes how homosexuals choose whether to identify, and whether to be open about their sexuality (MWLD) or to hide it (MWLD, OALD), a unique kind of inner turmoil that is at no time incited in heterosexuals. These MLDs describe a transsexual as a man who is made into a woman (LED, MWLD), or who tries to act like the opposite sex (CLD, OALD), which implies that they are still considered male until, at least, they change their physical body through a medical operation (MEDAL, OALD).

Following the above logic, trans* people are thus depicted as necessarily wanting to change, and actively changing themselves, into something else in order to conform to a stable male/female binary. Unlike the third way of being of the hijra, these definitions actively exclude a binarybending gender performance. Trans* persons are instead shown to be invalid persons as long as they are liminal-somewhere inbetween. What's more, any potential acts of resistance (through appearance, behaviour, dress, and so on) are slickly reinterpreted as acts of conformity. The MLD reader is offered only one explanation for a gender performance that does not appear to correspond with the performer's sexed body: the transsexual man is trying to look, dress, and act like a woman (CLD, MWLD, OALD). This rather narrow explanation does not allow for other possible motivations for a consciously queer gender performance, such as a wish to parody or to disrupt the very notion of gender by flouting its conventions. In this way, non-normative possibilities are erased; transgender as a rejection of identity is unmentioned, and unmentionable.

Apparently even ambiguously sexed bodies are indescribable and incoherent outside of a two-sex model, for intersex is defined by being "partly male and partly female" (OALD). Intersex bodies, when they are made visible at all, are read as an aberration; they are compared against the otherwise accepted 'fact' that material bodies are either fully male or fully female, rather than possibly posing a challenge to the (flawed) logic of the sex binary itself. That the term was absent from four of these five MLDs is further evidence for the systematic erasure of bodies that threaten the assumptions of the heterosexual matrix.

The MLD reader is given the sense that people are also self-reflexive about their sexuality and how its expression meshes with how they wish or feel it ought to be. Sexuality is seen to be an aspect of one's self with which one feels comfortable (MWLD) or confused (OALD), and the LED and OALD make plain the connections between sexuality, gender and sex, so that these are either 'correctly' aligned with each other, in accordance with the heteronormative matrix 
based on the two-sex binary, or out of alignment and therefore abnormal.

One MLD refers to "homosexual affairs" (MWLD), but nowhere is there mention of "heterosexual affairs". This suggests that, in the popular imagination, queer sexuality is associated with extramarital relationships, which makes sense, considering longstanding exclusion from the institution of marriage. Having an affair, like homosexuality, is seen as an act that takes sex outside of its rightful place within the confines of the reproductive nuclear family unit, and is thus frowned upon. Through the selective conflation of same-sex relations and adultery/promiscuity, the language of the MWLD strengthens the association in the reader's mind between homosexuality and sexual and moral deviance.

Finally, the MLD treatments of marriage and civil partnership are problematic in that they read like an outdated history of a social union currently in the midst of an international legal revolution. The two types of unions are explicitly compared so as to highlight that a civil partnership is a facsimile of marriage, a union similar to marriage (MEDAL), but not quite. So vital is the institution of marriage to society, and so urgently must homosexuals try to conform to it, that same-sex civil partnerships strive to look and act just like legitimate (i.e., one man, one woman; LED, MEDAL, MWLD) marriages.

Within the narrative of English learner's dictionaries, straight folk are the archetype while lesbian, gay, and bisexual folk are glossed over, trans* folk are crudely (mis)represented and intersex folk are largely overlooked. When these discursive constructions are consensually accepted as natural and social fact, queer voices and viewpoints are stifled and much of the diversity and nuance of the human experience is lost. To anybody who is new to the language, it becomes clear that English is far from queer-friendly.

\section{Legitimacy, Citizenship \& Governance}

M. Jacqui Alexander (1994), who writes on legitimacy and citizenship through feminist and queer perspectives, argues that the nation-state controls citizens' sexualities in order to maintain its own legitimacy-its lawful authority to rule. She finds that there is a "heterosexual imperative of citizenship" (p. 6) to be reproductive through conjugal, reproductive male/female coupling as a show of civic responsibility. Since the heterosexual family is "the form of family crucial in the state's view to the founding of the nation" (p. 20 ), the nation-state endorses heterosexism while simultaneously fearing nonreproductive queer bodies as imagined nonparticipants in the essential heteronormative institutions of marriage and family and therefore as threats to legitimacy. All of this reinforces the belief that queer persons are imperfect citizens because their sexualities are inauthentic and illegitimate, as evidenced by their position in social, academic, medical, political (national and international), and legal spheres of influence.

Despite the Canadian state's ostensible commitment to promoting multiculturalism, immigrants may encounter accusations of nonconformity in everyday life if they cling to their old culture and language; likewise, queers are construed as rebellious if they 'flaunt' their sexuality, rather than hiding their gayness (MWLD), or eschew the vital institutions of marriage and nuclear family, or enter into a 'civil partnership' with someone of the 'wrong' sex. Warner (1993) contends that queers understand that their "stigmatization is connected with gender, the family, notions of individual freedom, the state, public speech, consumption and desire, nature and culture, maturation, reproductive politics, racial and national fantasy, class identity, truth and trust, censorship, intimate life and social display" (xiii), and many other aspects of social life. The same can be said for English language learners and immigrants who are sexual minorities: 
'Sexual migrants' are those migrants seeking 'greater sexual equality and rights,' or at least some distance from sexualityrelated discrimination or oppression, and their numbers are on the rise [...] Other gay immigrants are motivated not so much by a need to flee persecution as a desire to be with their partner (or to find a partner), or simply to enjoy the possibility of having sexual or romantic relationships in a less oppressive environment. (Nelson 2010:446-7)

Once sexual migrants enter the ELL classroom, however, there is no guarantee that they will be immersed in a more queerfriendly environment. Is it typically teachers, to a far greater extent than students, who are vested with the authority to lead the learning environment and direct group discussions; language teachers, therefore, can exercise the power to promote some discourses as legitimate and others as inappropriate for the classroom. Nelson (2010) maintains that "gay topics and perspectives are constructed as unspeakable in the language classroom" ( $p$. 441); she finds that 'Pablo', a gay immigrant ELL and the subject of her case study, found it "difficult, if not impossible, to challenge the shutting down of gay topics when he found this disturbing; to raise gay topics himself; or[...] to explain his frustration that he could not legally marry a partner in either his home country or his new country" (p. 459). Permission of a particular discourse in the classroom to the exclusion of others also restricts learners' abilities to learn about themselves, their peers, and the world at large. Finally, the governance of queer talk in the ESL classroom hampers sexual minorities' ability to form crucial social networks with others like themselves (p. 454).

\section{DISCUSSION AND CONCLUSION}

New citizens are expected to
demonstrate their legitimacy through assimilation, which is achieved through mimicry of the imagined good or perfect citizen. For queer persons, this means performing heterosexual gender norms, hiding their 'gayness' (MWLD, OALD), and entering into marriage or a legal union 'similar to marriage' (MWLD). In other words, queer folk are expected to replicate the nuclear family as closely as possible, despite their bodies' imagined lack of reproductive ability. The ELL non-citizen/new citizen is similarly expected to assimilate into Englishspeaking culture by embracing new cultural norms and by speaking 'proper' English as it is presented MLDs and other ESL resources, which are, as ideological documents, highly reflective of heteronormative attitudes. Queer English language learners, then, are doubly alienated within the dominant heterosexual culture where queer desires are marginalised, gender identities are invalidated, and possibilities of sexual expression are erased. They are thus impelled to embody the ideal citizen with all the more zeal, in both language and behaviour, in order to achieve validity within the nation-state. The more proficient an ELL becomes in English, and the more a queer body conforms to the heterosexual matrix, the more closely they are seen to comply with mainstream cultural expectations and thus to resemble the ideal, legitimate citizen.

The currents of colonialism, globalization and the Information Age have no doubt facilitated the worldwide circulation of the rigid cultural ideas and ideals like compulsory heterosexuality. Queer English speakers can resist the colonization of their minds by acknowledging that every language is rooted in a cultural context and choosing to critically consider all that seems normal about sex, gender and sexuality. At the same time, as English is increasingly the de facto dominant language of international business, mass media, and the Internet, a common language can allow sexual minorities from around the world to communicate across 
borders, forming safe spaces where they can reflect on lived experiences and, ultimately, be the authors their own narratives.

Finally, educators who wish to support and validate diverse populations would do well to reflect on the ideological undercurrents of the instructional materials in their language curriculum. The erasure of queer realities and possibilities is a pertinent issue not only in language pedagogy, but also for educational, medical, immigration, youth, and other social support services and organizations seeking to support a multicultural, multilingual, multisexual citizenry.

\section{References}

Alexander, M. Jacqui. 1994. "Not Just (Any) Body Can Be a Citizen: The Politics of Law, Sexuality and Postcoloniality in Trinidad and Tobago and the Bahamas." Feminist Review 48:5-23.

Ball, Matthew B. "Dictionaries and Ideology: The Treatment of Gays, Lesbians and Bisexuals in Lexicographic Works." Master's thesis, School of Translation and Interpretation, University of Ottawa, 1998. Accession Order No. AAT MQ36658. Retrieved July 15, 2013 http://www.ruor.uottawa.ca/en/han dle $/ 10393 / 4466$

Baxter, James. 1980. "The Dictionary and Vocabulary Behavior: A Single Word or a Handful?" TESOL Quarterly 14(3):325-336.

Bury, Liz. 2013. “Macmillan Dictionary revises definition of marriage to include same-sex couples". theguardian.com. Retrieved September 7, 2013 http://www.theguardian.com/books/ 2013/aug/21/macmillan-dictionaryrevises-definition-gay-marriage

Butler, Judith. 1988. "Performative Acts and Gender Constitution." Theatre Journal 40(4):519-531.

Butler, Judith. 1990. Gender Trouble: Feminism and the Subversion of Identity. New York: Routledge.
Cambridge Learner's Dictionary. N.d.. Cambridge University Press.

Retrieved December 1, 2012 http://dictionary.cambridge.org/dicti onary/learner-english

Foucault, Michel. 1990. "Incitement to Discourse." The History of Sexuality, an Introduction. New York: Vintage, 1:1735.

Gannon, Shane. 2011. "Exclusion as Language and the Language of Exclusion: Tracing Regimes of Gender through Linguistic Representations of the 'Eunuch.'” The Journal of the History of Sexuality 20(1):1-27.

GLAAD. N.d. "GLAAD's Transgender Resources." Retrieved from http://www.glaad.org/transgender

Goulet, Jean-Guy A. 1996. "The 'Berdache'/'Two-spirit': A Comparison of Anthropological and Native Constructions of Gendered Identities among the Northern Athapaskans." Journal of the Royal Anthropological Institute 2(4):683701.

Longman English Dictionary Online. N.d. Pearson ELT. Retrieved December 1, 2012 http://www.ldoceonline.com

Macmillan English Dictionary for Advanced Learners. N.d. Macmillan Publishers Ltd. Retrieved December 1, 2012 http://www.macmillandictionary.co $\underline{\mathrm{m}}$

Merriam-Webster's Learner's Dictionary. N.d. Merriam-Webster, Inc. Retrieved December 1,

2012

http://www.learnersdictionary.com

Morgan, Joe. 2013. "Oxford Dictionary Says Marriage Definition Will Change to Include Gay People." gaystarnews.com, July 24. Retrieved September 7, 2013 http://www.gaystarnews.com/article Loxford-dictionary-says-marriagedefinition-will-change-include-gaypeople240713 
Nanda, Serena. 1985. "The Hijras of India: Cultural and Individual Dimensions of an Institutionalized Third Gender Role." Journal of Homosexuality, 11(3/4):35-54.

Nelson, Cynthia D. 2010. “A Gay Immigrant Student's Perspective: Unspeakable Acts in the Language Class." TESOL Quarterly, 44(3):441-464.

Oxford Advanced Learner's Dictionary. N.d.. Oxford University Press. Retrieved December 1, 2012 http://oald8.oxfordlearnersdictionari es.com

Valentine, David. 2006. "I Went to Bed with My Own Kind Once': The Erasure of Desire in the Name of Identity." Pp. 245-257 in The Language and Sexuality Reader, edited by Deborah Cameron and Don Kulick. New York: Routledge.

Warner, Michael. 1993. "Introduction." Pp. vii-xxxi in Fear of a Queer Planet: Queer Politics and Social Theory, edited by Michael Warner. Minneapolis, MN: University of Minnesota Press. 


\section{Appendix}

Definitions were retrieved from five English learner's dictionaries from major publishers, all of which are available online: Cambridge Learner's Dictionary (CLD), Longman English Dictionary Online (LED), Macmillan English Dictionary for Advanced Learners (MEDAL), Merriam-Webster's Learner's Dictionary (MWLD), and Oxford Advanced Learner's Dictionary (OALD).

Bisexual persons are sexually attracted to both men and women (CLD; LED; MEDAL; MWLD; OALD). Women and men define themselves as a bisexual (MWLD).

A civil partnership is a legal or officially recognized (CLD; LED; OALD) relationship, similar to marriage (MEDAL) between two people of the same sex (CLD; LED; MEDAL; OALD), which gives them the same legal rights as two people (a man and a woman) who are married (CLD; LED, OALD).

Females are women or girls (CLD; LED; MWLD; OALD), or the sex that can give birth to young or produce eggs (CLD; LED; MEDAL; MWLD; OALD). Females are not male (LED). Females have reproductive organs (OALD); they have feminine voices and names (MWLD). There are female characteristics, roles, and "female preserves" - things only women do (OALD), There are female vocalists (CLD), voters (LED), athletes (MWLD), students, employees, and artists (OALD).

Gay describes a homosexual person (CLD; LED; OALD), especially a man (CLD; MEDAL; LED; OALD), who is sexually attracted to people of the same sex (LED; OALD; MEDAL; MWLD). It is the opposite of straight (OALD). There is a gay community (LED; MEDAL) and a gay rights/gay pride movement (LED; MWLD), as well as gay bars and clubs (LED; MEDAL). Correct usages include "he is no longer trying to hide his gayness" (MWLD), "I didn't know he was gay" (OALD) and "is she gay?" (OALD).

Gender is the fact or state of being male or female (CLD; MEDAL; MWLD; LED; OALD), one of two separate groups (MEDAL), especially when considered with reference to social and cultural differences, not differences in biology (OALD). It is synonymous with sex (MWLD). It is asked for on forms (MWLD). There are gender differences (LED; OALD) and traditional gender roles exist (LED; MEDAL; OALD). Stories and toys may deal with gender issues, or reinforce gender biases or stereotypes (LED), but gender discrimination is forbidden (LED; MEDAL).

Heterosexuals are sexually attracted to people of the opposite sex (CLD; LED; MEDAL; MWLD; OALD). There is heterosexual behaviour (MWLD) and heterosexual relationships (OALD).

A homosexual is someone, especially a man (CLD; LED; OALD; MEDAL) who is sexually attracted to people of the same sex (CLD; LED; MEDAL) and not to people of the opposite sex (CLD). The term homosexual is somewhat formal (MWLD); male homosexuals are often called gays (MEDAL). Homosexuality is expressed through homosexual behaviour (MWLD), homosexual acts (OAD), homosexual relationships (LED, OALD), and homosexual affairs (MWLD). One can be a practicing homosexual (OALD) or be "very open about his homosexuality" (MWLD).

Intersex is the physical condition of being partly male and partly female (OALD). The term is absent from the CLD, LED, MEDAL, and MWLD.

A lesbian is a woman who is sexually attracted to other women (CLD; MEDAL; MWLD; LED; OALD), a female homosexual (MEDAL; MWLD). There are lesbian relationships and lesbian communities (OALD).

Males are men or boys (CLD; MWLD), or the sex that fertilizes eggs (CLD) and does not/cannot produce or give birth to babies (CLD; MEDAL; OALD). They have male voices (CLD; MWLD) and names (MWLD). There are male students (CLD), colleagues (MEDAL; OALD) and workers (MEDAL), athletes (MWLD), male nurses and models (OALD). Many women earn less than their male colleagues (CLD).

Marriage is a legally accepted (CLD; OALD) relationship between a woman and a man (CLD), or two people (LED; MEDAL), who live as husband and wife (CLD; MEDAL; 
MWLD; OALD). A man proposes marriage to his girlfriend (MWLD). People have long and happy marriages (CLD; LED; MEDAL; MWLD) and too many marriages end in divorce (LED; MEDAL; OALD). Some couples live together before marriage (MWLD) and some have children from previous marriages (LED; OALD). Many births occur outside of marriage (LED). In Denmark, they have legalized marriage between gay couples (LED).

Queer is an informal (CLD; MWLD), offensive (CLD; LED; MWLD; OALD), taboo (LED; OALD), slang (OALD) word for homosexual (CLD; LED; OALD), gay, bisexual, or transgender (MEDAL). One should not use this word (LED). However, it is also now sometimes used in a positive way for referring to people who are gay, bisexual, or transgender (MEDAL; MWLD), especially by people who are members of these groups (MEDAL; MWLD; OALD). Queer culture (MWLD) and queer studies (MEDAL; MWLD) exist.

A same-sex marriage is a marriage (LED), or a relationship similar to marriage (MWLD), between two men or two women (LED; MWLD). There are opponents and supporters of same-sex marriage (MWLD).

Sex is the fact or state of being male or female (CLD; MWLD; OALD), one of two separate groups (CLD; LED; MEDAL; MWLD; OALD), according to the function of producing young (OALD). It is synonymous with gender (MWLD; OALD). Babies have a sex (MEDAL; MWLD; OALD). Testosterone is the male sex hormone (OALD). 'Forms' will ask for your sex, along with your name, and age/date of birth (LED; MWLD; OALD). It is said that men are the more aggressive sex (MWLD) while women are the fair sex (OALD). Social interaction between the sexes can be difficult or competitive (LED; MEDAL; OALD). Sex discrimination exists (MWLD) but it is unjust (MEDAL; OALD).

Sexuality, i.e., male/female sexuality (LED; OALD), is defined by sexual feelings (CLD; LED; MEDAL; OALD), thoughts (LED), desires (LED; MWLD; OALD), attitudes (MEDAL), or preferences (CLD), as well as sexual habits (MWLD) and activities (LED;
MEDAL; OALD). There are 'types' of sex (CLD). Human sexuality is studied (MEDAL; OALD), specifically male sexuality (LED; MWLD). It is correct to say, for example, "she is comfortable with her sexuality" (MWLD) or "he was confused about his sexuality" (OALD).

Transgender describes people who have a sexual identity that is not clearly male or female (MWLD), or who feel that they belong to the other sex, and not the sex they were born with (LED), and who express this in their sexual behaviour (LED). There is a transgender community (LED; MWLD) and transgender issues (LED; MWLD; OALD). It relates to transsexualism (LED; MEDAL; OALD) and transvestism (OALD).

A transsexual is a person, especially a man (CLD), who want to be and feels that they should have been the opposite sex (CLD; LED), and tries to look, dress, and act like a member of that sex (CLD; MWLD), has a medical operation to change their sexual organs (MEDAL; OALD), or changes into a member of the opposite sex (LED; MWLD). A transsexual can also be a woman who wants to become a man (MEDAL). There are transsexual issues (MWLD). It is related to transvestism (LED; MWLD). An informal term for a transsexual is tranny (OALD).

A final note: in July 2013, following the legalization of same-sex marriage in England and Wales, the Oxford University Press announced that it would consider modifying the Oxford English Dictionary definition of marriage to mirror shifting usage (Morgan 2013). As of August 2013, the MEDAL has changed its definition of marriage to include same-sex relationships, and may similarly revise the terms 'husband' and 'wife' in the future (Bury 2013). 